\title{
Seed Preconditioning with Natural and Synthetic Antioxidants Induces Drought Tolerance in Tomato Seedlings
}

\author{
Mason T. MacDonald and Rajasekaran R. Lada ${ }^{1}$ \\ Department of Plant and Animal Sciences, Nova Scotia Agricultural College, \\ Cox Institute, P.O. Box 550, Truro, NS B2N 5E3, Canada
}

\section{A. Robin Robinson and Jeff Hoyle \\ Department of Environmental Sciences, Nova Scotia Agricultural College, Truro, NS, Canada, B2N 5E3}

Additional index words. Ambiol ${ }^{\circledR}$, ascorbic acid, $\beta$-carotene, drought tolerance, isoelectric focusing, lutein, lycopene, seed preconditioning agents

\begin{abstract}
There is strong evidence that Ambiol $^{\circledR}$ (a derivative of 5-hydroxybenzimazole) promotes drought tolerance in many plants; it is often suggested that this is the result of its antioxidant properties. Recent evidence has also shown that several natural antioxidants promote carrot germination under drought stress. Thus, it was hypothesized that seed preconditioning using natural antioxidants might confer drought tolerance. Ambiol ${ }^{\circledR}$, ascorbic acid, $\beta$-carotene, lutein, and lycopene were chosen as antioxidants at concentrations of $0.1 \mathrm{mg} \cdot \mathrm{L}^{-1}, 1.0 \mathrm{mg} \cdot \mathrm{L}^{-1}$, and $10 \mathrm{mg} \cdot \mathrm{L}^{-1}$. A preconditioning treatment was applied by soaking tomato (Solanum lycopersicum L.) seeds in an antioxidant solution for $24 \mathrm{~h}$. Of the antioxidants tested, $10 \mathrm{mg} \cdot \mathrm{L}^{-1} \mathrm{Ambiol}{ }^{\circledR}, 1.0 \mathrm{mg} \cdot \mathrm{L}^{-1}$ $\beta$-carotene, $1.0 \mathrm{mg} \cdot \mathrm{L}^{-1}$ ascorbic acid, and $0.1 \mathrm{mg} \cdot \mathrm{L}^{-1}$ lycopene were shown to increase shoot dry mass by $114 \%, 94 \%, 56 \%$, and $83 \%$, respectively, in droughted seedlings when compared with a droughted control. Similar benefits were observed in root dry mass, leaf area, photosynthesis, and water use efficiency. Proteins were extracted from the seeds of certain treatments, before and after germination, and separated using isoelectric focusing. Specific proteins were found to be induced through all preconditioning treatments, whereas Ambiol ${ }^{\circledR}$ and $\beta$-carotene were found to induce specific proteins, independent of those induced through imbibition, both before and after germination. This result suggests that Ambiol ${ }^{\circledR}$ and $\beta$-carotene evoke specific proteins that may confer drought tolerance to the key physiological processes studied. In addition, protein profiles of ascorbic acid, $\beta$-carotene, and Ambiol ${ }^{\circledR}$ after germination had fewer visible bands than the controls, suggesting an accelerated mobilization or conversion of proteins within the seed.
\end{abstract}

Drought is a major problem for agriculture productivity and profitability. Between 1987 and 1989, losses from drought were estimated at \$39 billion in the United States (OTA - Office of Technology Assessment, 1993). The 1996 drought in Texas alone caused a $\$ 6.5$ billion loss to agriculture (Wilhite and Vanyarkho, 2000). In 1995, the U.S. Federal Emergency Management Agency, as part of a national mitigation strategy for all natural hazards, estimated that droughts in the United States cause an average annual economic loss of $\$ 6$ to $\$ 8$ billion, the highest estimate of any hazard (FEMA-Federal Emergency Management

Received for publication 9 Jan. 2009. Accepted for publication 6 May 2009.

We acknowledge the contribution made by Hai Choo Smith in helping with the isoelectric focusing and staining procedure. We thank Dr. Claude Caldwell and Dr. Kevin Sibley for their comments and suggestions during internal revision of the manuscript. We also thank the Natural Sciences and Engineering Research Council (NSERC) for funding this research.

${ }^{1}$ To whom reprint requests should be addressed; e-mail rlada@nsac.ca.
Agency, 1995). Economic consequences of drought are felt equally as hard in Canada. In 1988 and 2001, agricultural economic losses for Canada were estimated to be over $\$ 5$ billion (Phillips, 2002; Wheaton et al., 1992).

Periods of drought (in the order of days or weeks) can be harmful to the plant, decreasing plant growth and yields in several ways. Decreased leaf expansion results in a decline in photosynthesis, resulting in a reduction in carbon fixation and ultimately plant senescence (Shulze, 1986). In addition, a decrease in root zone water potential results in partial or complete closure of stomata (Kaufmann, 1981). Continued stomatal closure triggers photooxidative reactions, free radical generation, and membrane destabilizations, releasing cell content into the apoplast leading to dehydration, desiccation, and death (Rajasekaran and Blake, 1999).

Several technologies exist to help mitigate drought; one such technology is seed preconditioning. Seed preconditioning is the process of treating seeds with certain compounds, often called seed preconditioning agents (SPAs), in an attempt to confer some specific benefit to the plant, whether it be to improve germination rate, vigor, stress toler- ance, or yield (Rajasekaran and Blake, 1999). While priming, seeds are exposed to an external water potential low enough to restrict germination but high enough to allow pregerminative physiological and biochemical processes to occur (Bradford, 1986). It is suggested that further amplification of these physiological and biochemical responses using SPAs can help maximize the benefits to plants (Khan, 1992).

Many compounds have been used as SPAs. Rajasekaran et al. (2004) have found that $1 \mathrm{mg} \cdot \mathrm{L}^{-1}$ salicylic acid and $1 \mathrm{mg} \cdot \mathrm{L}^{-1}$ and $100 \mathrm{mg} \cdot \mathrm{L}^{-1}$ acetylsalicylic acid were effective at promoting the germination of carrot below $5{ }^{\circ} \mathrm{C}$. Recently, Rajasekaran et al. (2005) have also found that Bioprotect ${ }^{\circledR} 2$ (a conifer-derived phenolic compound; discovered by Dr. Lada, NSAC, Truro, Nova Scotia, Canada) and glycinebetaine (a quaternary ammonium compound) effectively promote drought tolerance in carrots. Another compound of particular interest as a SPA is a synthetic antioxidant called Ambiol ${ }^{\circledR}$, derived from 5-hydroxybenzimidazole, which stimulates growth in several species and acts as an antistress (MacDonald et al., 2008; Rajasekaran and Blake, 1999, 2002; Rajasekaran et al., 2005), antioxidant (Santrucek and Krepelka, 1988; Voronina et al., 2001), and antitranspirant compound (Darlington et al., 1996). Based on the work of Rajasekaran and Blake (2002), it has been shown that preconditioning carrot seeds with $10 \mathrm{mg} \cdot \mathrm{L}^{-1}$ Ambiol ${ }^{\circledR}$ can promote dry matter production under drought conditions by as much as $214 \%$ when compared with a droughted control. Also, Ambiol ${ }^{\circledR}$ is effective at promoting growth in tomato seedlings under moisture deficit through increased photosynthesis, leaf area expansion, and water use efficiency (MacDonald, 2006; MacDonald et al., 2008). It has been proposed that Ambiol ${ }^{\circledR}$ functions by offering membrane protection to maintain photosynthesis as well as promoting root growth while decreasing transpiration to increase plant water potential. The net effect of decreasing transpiration and increasing photosynthesis is a higher water use efficiency (Rajasekaran and Blake, 2002).

Carotenoids are a class of natural fatsoluble pigment antioxidants found principally in plants, algae, and photosynthetic bacteria. The majority of carotenoids are derived from a 40-carbon polyene chain and may be ended with cyclic or oxygen-containing functional groups. Hydrocarbon carotenoids such as $\beta$-carotene or lycopene are known as carotenes, whereas oxygenated carotenoids such as lutein are known as xanthophylls (Ong and Tee, 1992). Traditionally, carotenoids protect the photosynthetic system from photo-oxidative damage (Bartels and Watson, 1978); investigation into their role as SPAs has been limited.

The mode of action of $\mathrm{Ambiol}^{\circledR}$ in conferring drought tolerance has often been associated with Ambiol's role as an antioxidant. If Ambiol induces drought tolerance as a result of its antioxidant activity, then one might hypothesize that similar drought 
tolerance would result from other antioxidant compounds. However, such physiological acclimation cannot be ascribed to the direct effect of these compounds, but perhaps be the result of these compounds triggering specific proteins in the seeds. Thus, it may be possible that the potent action of these compounds in enhancing drought acclimation may be the result of expression of a specific protein. The objectives of this study were 1) to determine if Ambiol and natural occurring antioxidants lutein, lycopene, $\beta$-carotene, and ascorbic acid used as seed preconditioning agents offer drought protection to tomato seedlings; and 2) to determine if there are differences in the protein expression of tomato seeds resulting from preconditioning with antioxidants.

\section{Materials and Methods}

Seed preconditioning. Natural antioxidants lutein, lycopene, $\beta$-carotene, and ascorbic acid (Sigma-Aldrich Canada Ltd., Oakville, Ontario, Canada) were used as preconditioning agents along with a synthetic antioxidant 2methyl-4-[dimethylaminomethyl]-5-hydroxybenzimidazole (Ambiol ${ }^{\circledR}$ Inc., Ontario, Canada). Initially, all antioxidants were made into a $10 \mathrm{mg} \cdot \mathrm{L}^{-1}$ solution. For water-soluble antioxidants, Ambiol ${ }^{\circledR}$ and ascorbic acid, $2.5 \mathrm{mg}$ was dissolved in $250 \mathrm{~mL}$ distilled water. For waterinsoluble antioxidants, lutein, lycopene, and $\beta$-carotene, $1 \mathrm{mg}$ was first dissolved in $1.6 \mathrm{~mL}$ ethanol and then diluted in $100 \mathrm{~mL}$ distilled water. The $10 \mathrm{mg} \cdot \mathrm{L}^{-1}$ antioxidant solutions were diluted to make $1.0 \mathrm{mg} \cdot \mathrm{L}^{-1}$ and $0.1 \mathrm{mg} \cdot \mathrm{L}^{-1}$ solutions.

Tomato seeds (var. Scotia) (Stokes Seeds Ltd, St. Catherines, Ontario, Canada) were preconditioned using $0.1 \mathrm{mg} \cdot \mathrm{L}^{-1}, 1.0 \mathrm{mg} \cdot \mathrm{L}^{-1}$, and $10 \mathrm{mg} \cdot \mathrm{L}^{-1}$ solution of each of the compounds as well as in water and diluted ethanol (1.6 mL in $100 \mathrm{~mL}$ water to match ethanolsoluble antioxidants), which served as controls. Also, a nonpreconditioned control was used. Preconditioned tomato seeds were soaked for $24 \mathrm{~h}$ in a G24 Environmental Incubator Shaker (NB Scientific Co. Inc., Edison, NJ) at $25^{\circ} \mathrm{C}$ and $150 \mathrm{rpm}$. Afterward, the treated seeds were strained from solution and dried on paper towels as described by Rajasekaran and Blake (1999). Seeds were germinated in petri dishes with moistened filter paper to ensure they would grow once sown.

Growing conditions. Six plastic trays $(50 \mathrm{~cm} \times 36 \mathrm{~cm} \times 10 \mathrm{~cm})$ were filled with 3 kg Promix BX (Premier Horticulture Inc., Red Hill, PA). The trays were divided into two groups, one to be subjected to drought and the other served as a well-watered unstressed control. Each tray was subdivided into 30 portions in which each portion received one preconditioned seed to serve as a single replication. Seeds were randomly assigned with five replications per treatment for a total of 90 seeds. All trays were placed in a temperaturecontrolled growth chamber grown at $25{ }^{\circ} \mathrm{C}$ day $/ 10{ }^{\circ} \mathrm{C}$ night temperatures, 16 -h photoperiod, and fluorescent/incandescent lighting provided $300 \mu \mathrm{mol} \cdot \mathrm{m}^{-2} \cdot \mathrm{s}^{-1}$ light intensity.
Each tray received $1 \mathrm{~L}$ water daily, distributed manually using a watering can, which was sufficient to maintain $59.7 \% \pm$ $1.0 \%$ soil moisture as measured using a TDR 300 soil moisture probe (Spectrum Technologies, Plainfield, IL). Soil moisture measurements were taken daily as an average of six replications. On the 15 th day after emergence, drought was imposed on one group of trays by withholding water for $12 \mathrm{~d}$, lowering soil moisture to $4.1 \% \pm 1.6 \%$. The unstressed group continued to receive $1 \mathrm{~L}$ water each day.

Physiological measurements. On the 12th day of drought, an LCA4 photosynthetic unit (ADC BioScientific Ltd., Herts, U.K.) was used to monitor net photosynthesis (Pn), instantaneous transpiration (Tl), stomatal conductance $\left(g_{\mathrm{S}}\right)$, and instantaneous water use efficiency (WUE). Pn, Tl, and $g_{\mathrm{s}}$ were measured from the newest fully expanded leaf, starting at $0900 \mathrm{HR}$ and ending at $1300 \mathrm{HR}$ to minimize diurnal variation. WUE was calculated as the ratio of photosynthesis to transpiration as described in MacDonald (2006). Environmental conditions within the leaf cuvette were the same as those described for the incubation chamber. All parameters obtained from the LCA4 were based on the area of the LCA4 leaf chamber. Therefore, leaves on which measurements made were removed from the plant, placed on paper with a reference ruler, and photographed. The images of the photographed leaves were uploaded to CIAS 2.0 Image Measurement Software (Jandel Scientific, San Rafael, CA) to calculate actual leaf area. All LCA4 data were then adjusted to actual leaf area to determine actual Pn, Tl, $g_{\mathrm{s}}$, and WUE.

Membrane injury index (MII) was determined by removing fully expanded leaves and submerging them in $50-\mathrm{mL}$ tubes containing $30 \mathrm{~mL}$ of distilled water. The tubes were sealed and left at room temperature for $24 \mathrm{~h}$. Initial conductivity (ECo) was measured using a CDM 2e Conductivity Meter (BachSimpson, Ontario, Canada). Sealed tubes were placed in a forced-air oven for $4 \mathrm{~h}$ at $90{ }^{\circ} \mathrm{C}$ to kill tissues and then cooled to room temperature. Final conductivity measurements (ECk) were taken after equilibrating to $25{ }^{\circ} \mathrm{C}$. MII was then calculated using the formula $[(\mathrm{ECk}-\mathrm{ECo}) / \mathrm{ECk}]^{*} 100$ (Rajasekaran and Blake, 1999). Using this formula, a higher value for MII would suggest increased membrane stability.

Both root and shoot dry mass (DM) were measured. Each seedling was removed from the Promix and cleaned with running water. The roots were cut away from the shoot and then both were dried in a hot air oven at $80{ }^{\circ} \mathrm{C}$ for $48 \mathrm{~h}$ and then weighed dry to determine DM.

A one-way analysis of variance test using Proc GLM (SAS Institute, Cary NC) was used to determine statistical significance $(P<$ $0.05)$ in all response parameters. A quartic root transformation was imposed on the net photosynthesis data to induce normality. In the event of significant differences among treatments, least squares means of the treat- ment combinations were compared with generate letter groupings at the 5\% level of significance.

Protein extraction. Because seeds primarily undergo protein synthesis from newly synthesized mRNA after imbibition, it was necessary to analyze seeds that had gone through the remaining two phases of germination (Bewley, 1997). Therefore, half the treated seeds from each treatment were separated to undergo germination while the rest were stored at $4{ }^{\circ} \mathrm{C}$ immediately after preconditioning. The separated half of seeds were spread out on water-soaked filter paper in six different petri dishes (one for each treatment) at $20{ }^{\circ} \mathrm{C}$. Germination was determined to have been completed $5 \mathrm{~d}$ after preconditioning, when the majority of seeds had germinated and no new seeds were germinating each day.

Seeds from each treatment (before and after germination) were ground to powder using mortar and pestle. To prepare for protein extraction, $200 \mathrm{mg}$ of seed powder from each treatment was manually homogenized with glass rods in $300 \mu \mathrm{L}$ of $50 \% \mathrm{~N}, \mathrm{~N}-$ dimethylformamide (DMF) solution in microcentrifuge tubes. The glass rods were rinsed with $100 \mu \mathrm{L}$ of $50 \%$ DMF to make a total volume of $400 \mu \mathrm{L}$. The extracts were allowed to stand overnight at $4{ }^{\circ} \mathrm{C}$ and then vortexed for $2 \mathrm{~min}$ to mix. After vortexing, the extracts were centrifuged at $13,000 \mathrm{~g}$ for $20 \mathrm{~min}$. The supernatant was carefully collected using a $100-\mu \mathrm{L}$ pipette and stored at $-80{ }^{\circ} \mathrm{C}$ until isoelectric focusing (IEF).

Gel preparation. A $0.5-\mathrm{mm}$ thick gel was used, which required a total volume of $25 \mathrm{~mL}$ of gel solution $(6.25 \mathrm{~mL}$ acrylamide/bis solution, $1.9 \mathrm{~mL}$ ampholytes, $16.7 \mathrm{~mL}$ distilled water, $0.125 \mathrm{~mL}$ ammonium persulfate solution, and $0.125 \mathrm{~mL}$ TEMED solution). Initially the acrylamide/bis solution, ampholytes, and distilled water were mixed together and deaerated for $5 \mathrm{~min}$ in a vacuum flask. Then the ammonium persulfate and TEMED solutions were added and mixed by gentle swirling. The polyacrylamide gel solution was applied to the GelBand PAG film and placed between two glass plates separated by a $0.5-\mathrm{mm}$ thick spacer to enable easy handling during the staining procedures. After the gel was applied, the glass plate at the top was slid over the gel and with even pressure was applied over the surface to eliminate air bubbles and seal the film to the plate. Gel polymerization occurred within $1 \mathrm{~h}$.

Protein analysis. Tomato seed protein samples from the supernatants were prepared for gel electrophoresis by adding $5 \mu \mathrm{L}$ solubilizing buffer $(9.5 \mathrm{M}$ urea, $5 \mathrm{~mm}$ $\left.\mathrm{K}_{2} \mathrm{CO}_{3}, \mathrm{pH} 10.3\right)$ to $5 \mu \mathrm{L}$ of each sample. The extract and buffer mixture was sonicated.

The MultiTemp II thermostatic circulator (GE Healthcare Bio-Sciences Ltd., Piscataway, NJ) was set at $10{ }^{\circ} \mathrm{C}$ and the IEF system was allowed to warm up $15 \mathrm{~min}$ before the GelBand PAGfilm with the polymerized gel was applied to the cooling plate. After the film was placed on the cooling plate, the electrode strips were plugged into 
the cooling plate. Then $5 \mu \mathrm{L}$ of each of the samples was spotted onto the gel $1.5 \mathrm{~cm}$ apart using a $100-\mu \mathrm{L}$ pipette. The ampholytes used had a $\mathrm{pH}$ range of 3.5 to 9.5 because the $\mathrm{pH}$ of the extract was not known and a constant voltage of $500 \mathrm{~V}$ was applied to separate the proteins according to their isoelectric points (pI) (Hames, 1990). After $6 \mathrm{~h}$, the proteins migrated to the cell where the $\mathrm{pH}$ of the solution matches their $\mathrm{pI}$.

To create a clearly visible banding pattern, the gel was stained with silver, which binds only the proteins as described by Hames (1990). After destaining, the GelBand PAGfilm with the protein profiles was allowed to dry and then wrapped into a thin transparent plastic to prevent damage to the protein profiles. The GelBand PAGfilm was then tapped to a foolscap paper and the protein bands were labeled according to the names of the preconditioning treatments and controls.

\section{Results}

Plant growth. There was no significant improvement in leaf area expansion resulting from water or ethanol alone. However, ascorbic acid and $\beta$-carotene at $1.0 \mathrm{mg} \cdot \mathrm{L}^{-1}$ each significantly increased expansion by $70 \%$ compared with droughted controls (Fig. 1A). Also, $10 \mathrm{mg} \cdot \mathrm{L}^{-1}$ Ambiol $^{\circledR}$ was marginally significant $(0.05<P<0.1)$, increasing leaf area by $35 \%$ compared with the untreated control under drought. Lutein and lycopene treatments were not significantly different from the untreated control.

There was no significant increase in shoot DM resulting from water or ethanol alone. However, shoot DM was significantly increased during drought when seeds were preconditioned with several antioxidants. Seed preconditioning using $10 \mathrm{mg} \cdot \mathrm{L}^{-1}$ Ambiol ${ }^{\circledR}$ and $1.0 \mathrm{mg} \cdot \mathrm{L}^{-1} \beta$-carotene were the most effective, increasing shoot DM by $114 \%$ and $94 \%$, respectively, when compared with the untreated control under drought. Concentrations of $1.0 \mathrm{mg} \cdot \mathrm{L}^{-1}$ and $10 \mathrm{mg} \cdot \mathrm{L}^{-1}$ ascorbic acid, $0.1 \mathrm{mg} \cdot \mathrm{L}^{-1}$ lycopene, and $0.1 \mathrm{mg} \cdot \mathrm{L}^{-1}$ $\beta$-carotene preconditioning produced results that were also significantly higher than the untreated control under drought, ranging from a $47 \%$ to $83 \%$ increase in shoot DM (Fig. 1B).

There was no significant increase in root DM resulting from water or ethanol alone. Seed preconditioning with $10 \mathrm{mg} \cdot \mathrm{L}^{-1}$ of Ambiol ${ }^{\circledR}$ was the only statistically significant treatment increasing root DM by $105 \%$ when compared with untreated seedlings under drought. Concentrations of $0.1 \mathrm{mg} \cdot \mathrm{L}^{-1}$ lycopene, $1.0 \mathrm{mg} \cdot \mathrm{L}^{-1}$ lutein, and $1.0 \mathrm{mg} \cdot \mathrm{L}^{-1}$ ascorbic acid increased root DM by $35 \%$ to $75 \%$ under drought, but these results were only marginally significant $(0.05<P<0.1)$ (Fig. 1C).

Photosynthesis and membrane stability. Of all the treatments, only $1.0 \mathrm{mg} \cdot \mathrm{L}^{-1}$ of $\beta$-carotene significantly increased Pn under drought, albeit by $500 \%$ compared with the untreated control under drought (Fig. 2A). Seeds preconditioned with $1.0 \mathrm{mg} \cdot \mathrm{L}^{-1}$ ascorbic acid had a marginally significant increase
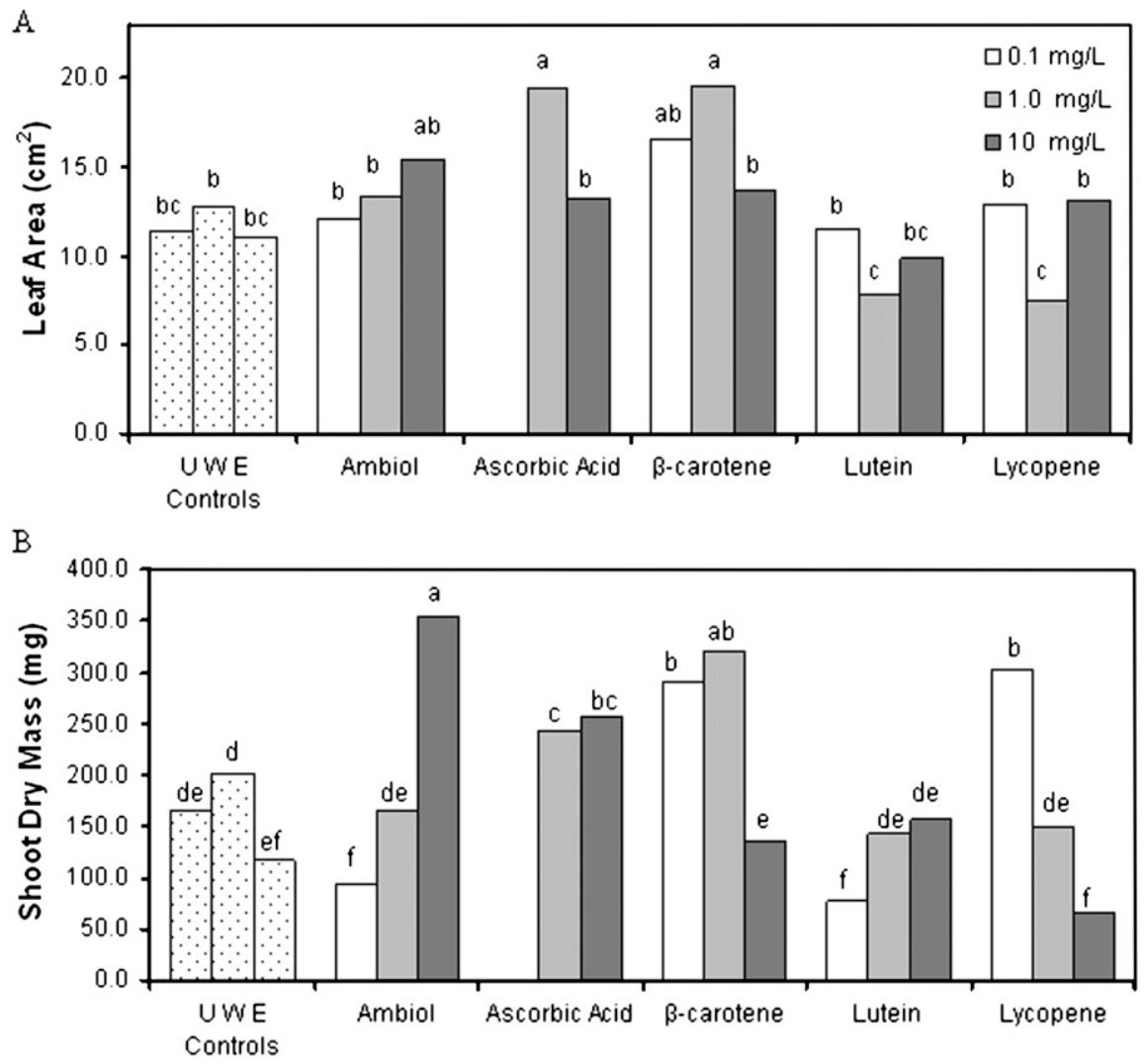

C

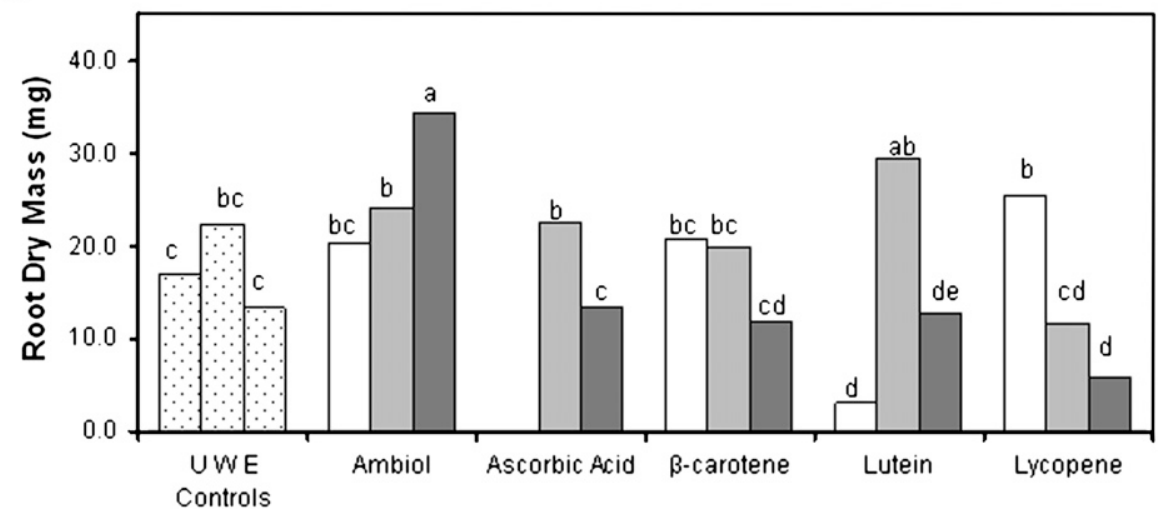

Fig. 1. (A) Leaf area expansion, (B) shoot dry mass, and (C) root dry mass of tomato seedlings exposed to drought. In all cases, $\mathrm{U}=$ untreated seeds, $\mathrm{W}=$ water only, and $\mathrm{E}=$ diluted ethanol. Letter groupings indicate a significant difference at $\alpha=0.05$. Means were calculated from five replications.

in Pn of $223 \%$. Several other concentrations, including seeds preconditioned with $0.1,1.0$, and $10 \mathrm{mg} \cdot \mathrm{L}^{-1} \mathrm{Ambiol}^{\circledR}$ as well as $0.1 \mathrm{mg} \cdot \mathrm{L}^{-1}$ and $10 \mathrm{mg} \cdot \mathrm{L}^{-1} \quad \beta$-carotene, had $\approx 2$-fold increases in $\mathrm{Pn}$, but a high degree of variability in Pn did not allow for detecting statistical significance.

Seedlings preconditioned with $10 \mathrm{mg} \cdot \mathrm{L}^{-1}$ Ambiol ${ }^{\circledR}$ maintained $168 \%$ higher $\mathrm{Tl}$ than the untreated control (Fig. 2B). Both $\beta$-carotene and ascorbic acid maintained $\mathrm{Tl}$, ranging from $37 \%$ to $100 \%$ higher than untreated controls $(P<0.1)$. Measurements of $g_{\mathrm{s}}$ corresponded with $\mathrm{Tl}$; those plants with a high Tl also had high $g_{\mathrm{s}}$ and vice versa.

Water alone had no effect on WUE, but ethanol significantly increased WUE by $150 \%$ when compared with the untreated control (Fig. 2C). Therefore, although $\beta$-car- otene also had an increase in WUE, it was likely the result of being dissolved in ethanol. However, $0.1 \mathrm{mg} \cdot \mathrm{L}^{-1} \mathrm{Ambiol}^{\circledR}$ significantly increased WUE by $221 \%$ when compared with the water-treated control. Also, $1 \mathrm{mg} \cdot \mathrm{L}^{-1}$ Ambiol ${ }^{\circledR}$ and ascorbic acid had an increase in WUE of $\approx 120 \%$ when compared with the water-treated control

$(P<0.1)$.

There was no clear benefit to MII resulting from preconditioning using any of the antioxidants (Fig. 3). However, $10 \mathrm{mg} \cdot \mathrm{L}^{-1}$ Ambiol ${ }^{\circledR}$ was the most effective treatment with a MII of $89.1 \%$, which was significantly higher than the untreated control under drought. However, the effect of Ambiol ${ }^{\circledR}$ was not significantly higher than the effect of water alone. Similarly, although $\beta$-carotene and ascorbic acid did enhance membrane 


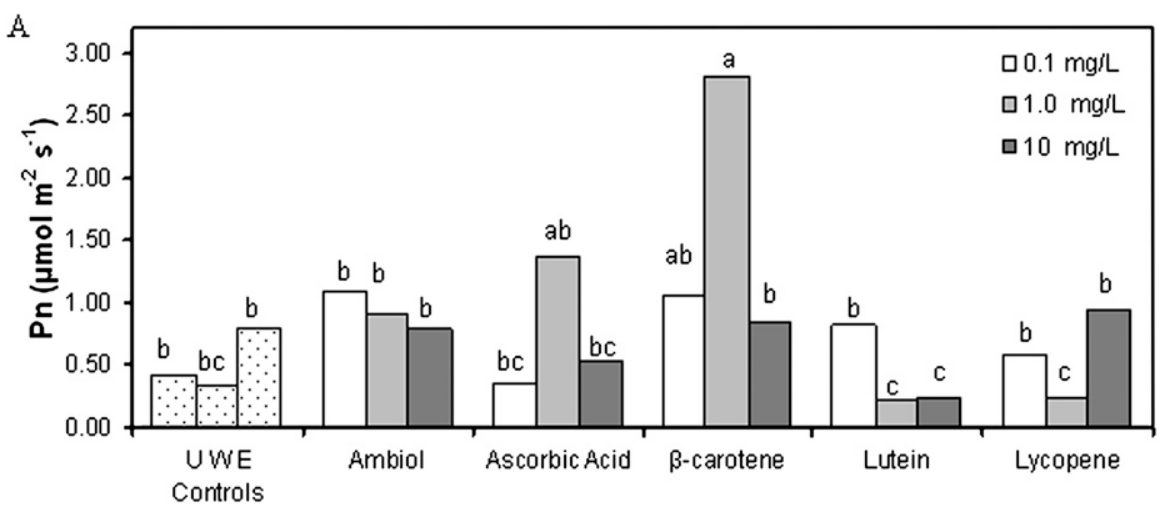

B

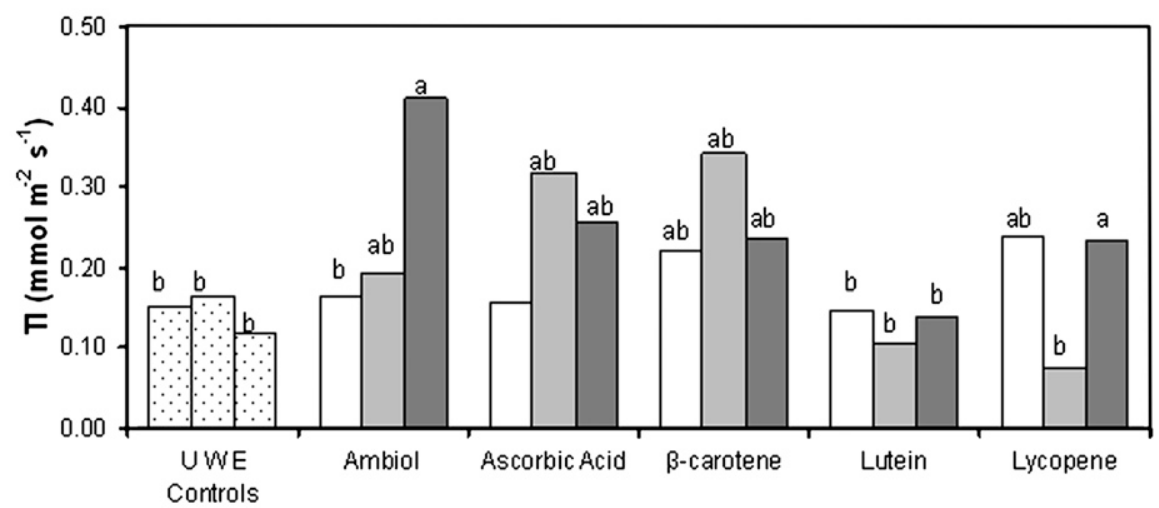

C

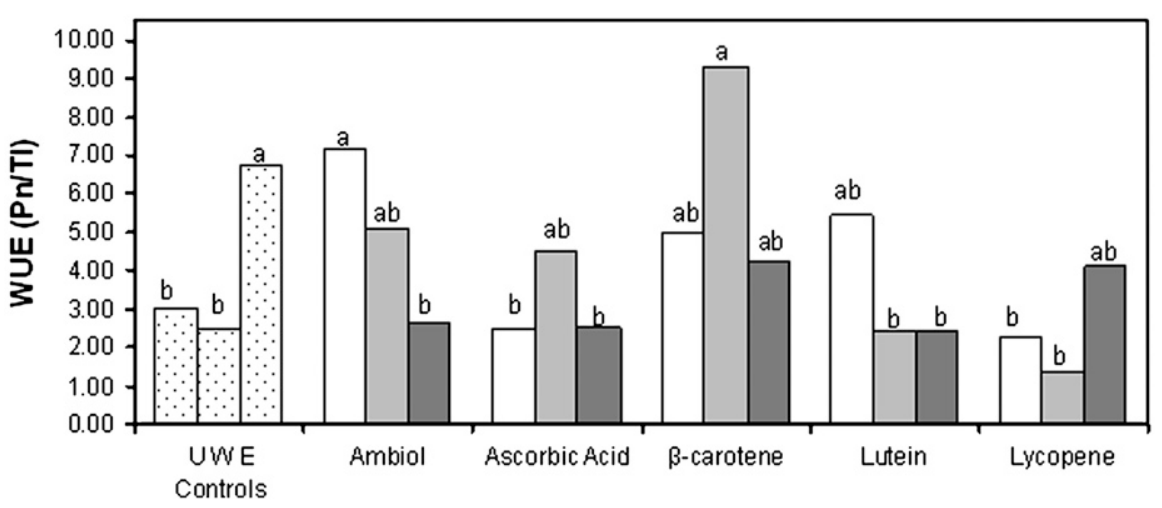

Fig. 2. (A) Net photosynthesis (Pn), (B) instantaneous transpiration (T1), and (C) water use efficiency (WUE) in tomato seedlings exposed to drought. In all cases, $\mathrm{U}=$ untreated seeds, $\mathrm{W}=$ water only, and $\mathrm{E}$ $=$ diluted ethanol. Letter groupings indicate a significant difference at $\alpha=0.05$. Means were calculated from five replications.

stability compared with the ethanol controls, the effects were was not statistically higher than only water.

Protein profile. Comparison of the protein profile of seeds before and after germination after preconditioning using certain natural and synthetic antioxidants shows an overall shift of protein bands to the right, increasing the number of proteins with a higher isoelectric point (Fig. 4). In all treatments, the general trend was for the band from reference point (RP) 0 to disappear, bands between RP 2.0 and RP 5.0 to be greatly reduced, and bands between RP 6.0 and RP 7.5 to be largely diminished. However, new protein bands were visible between RP 8.5 and RP 9.5. Also, there was a trend for the total number of protein bands to decrease after germination.
RP 9.2 to 9.7. Attempts to quantify the number of bands in each profile indicated an increase resulting from imbibition, but no additional protein bands were evident as a result of preconditioning. This result indicates a shift in expression of specific proteins rather than the number of protein bands and that the specific bands relating to each of the SPAs may be associated with the specific changes in physiology of tolerance to drought conferred by the SPA.

The overall trend after germination is a total decrease of protein bands. The only protein that disappeared was between RP 7.2 and RP 7.3, which may be associated with imbibition, induced activation of specific proteins relating to germination. New bands at RPs 6.0, 6.3, and 6.6 are ethanolspecific. Ambiol ${ }^{\circledR}$ and $\beta$-carotene induced expression of specific proteins at RPs 7.0, 7.5 to 7.7 , and 9.1 to 9.8 . Ambiol ${ }^{\circledR}, \beta$-carotene, and ascorbic acid all have induced specific proteins that are seen at RP 5.7 and RP 8.2 to 8.4. Perhaps the most interesting finding is that, contrary to the profiles before germination, the number of bands visible in SPA-treated seeds is far less than those treated with water or ethanol, suggesting an accelerated mobilization or conversion of proteins within the seed.

\section{Discussion}

Antioxidant-induced drought tolerance. Ambiol ${ }^{\circledR}$ was effective at promoting root and shoot dry mass production, leaf area expansion, net photosynthesis, and, to a degree, membrane protection. Although Ambiol ${ }^{\circledR}$ was successful at some level at all concentrations, the most benefit was seen at 10 $\mathrm{mg} \cdot \mathrm{L}^{-1}$. A $10 \mathrm{mg} \cdot \mathrm{L}^{-1}$ Ambiol $^{\circledR}$ pretreatment resulted in a $113 \%$ increase in DM, a $35 \%$ increase in leaf area, and a 7\% increase in MII compared with untreated seedlings. These results are consistent with previous results that found $10 \mathrm{mg} \cdot \mathrm{L}^{-1}$ Ambiol $^{\circledR}$ an effective treatment in tomatoes both with and without ABA deficiency (MacDonald and Rajasekaran, 2006; MacDonald et al., 2008).

The growth stimulation and membrane stabilization of Ambiol ${ }^{\circledR}$ in tomato seedlings supports previous results in some agricultural dicot species (Darlington et al., 1996) and conifers (Rajasekaran and Blake, 1999). The Ambiol ${ }^{\circledR}$ preconditioned tomato seedling results also correspond strongly with the results of Rajasekaran and Blake (2002) who reported a $214 \%$ increase in DM, 70\% increase in $\mathrm{Pn}$, and increased membrane capacitance in carrot seedlings treated with $10 \mathrm{mg} \cdot \mathrm{L}^{-1} \mathrm{Ambiol}^{\circledR}$. Interestingly, Ambiol did not reduce transpiration in tomatoes as has been noted in other studies (Darlington et al., 1996). However, Kirillova et al. (2003) noted that Ambiol increased $\mathrm{Pn}$ in potatoes while reducing $\mathrm{ABA}$. A reduction in $\mathrm{ABA}$ would limit stomatal closure under drought conditions, potentially explaining the higher rates of transpiration observed in tomatoes. 


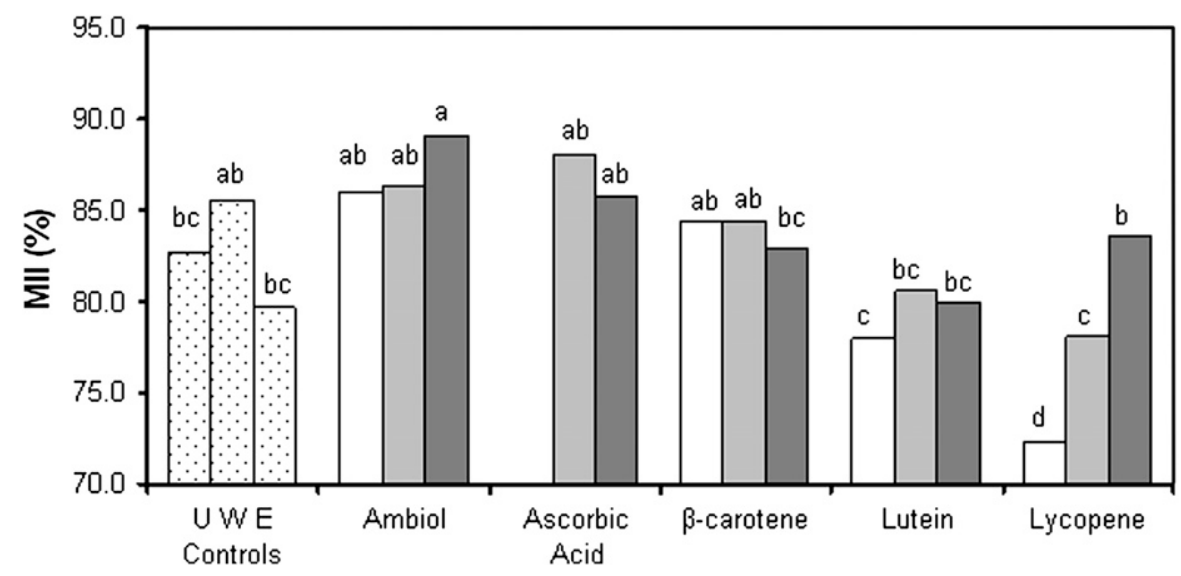

Fig. 3. Membrane injury index (MII) of tomato seedlings exposed to drought. $\mathrm{U}=$ untreated seeds; $\mathrm{W}=$ water only; and $\mathrm{E}=$ diluted ethanol. Letter groupings indicate a significant difference at $\alpha=0.05$.

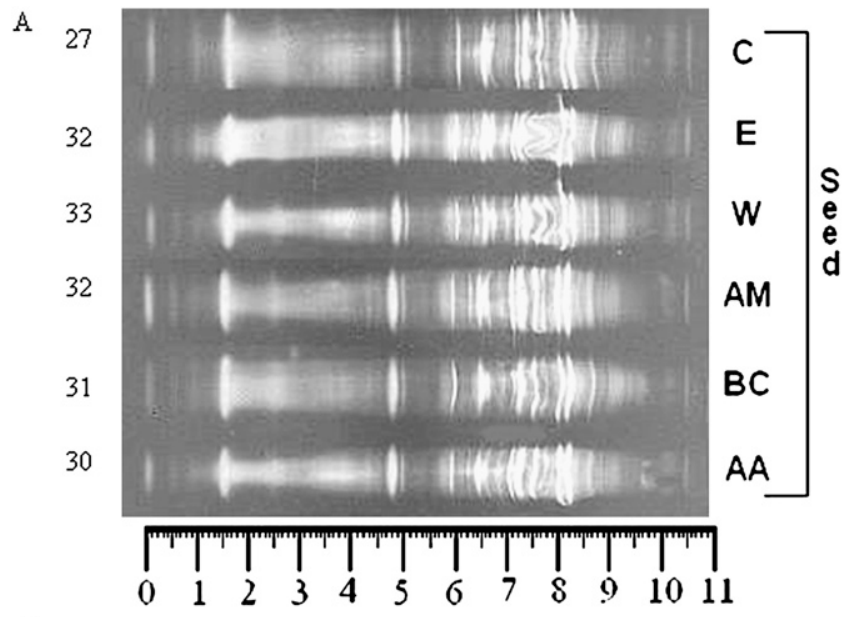

B

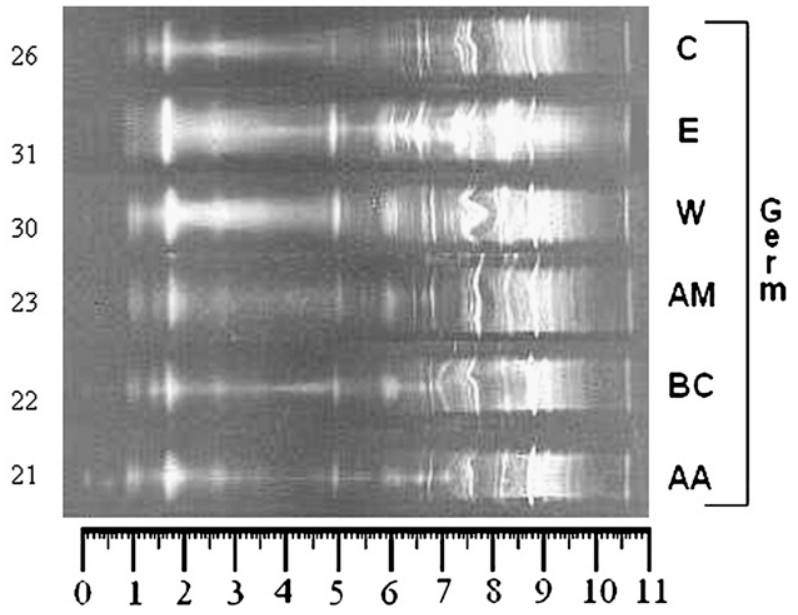

Fig. 4. Protein profile of (A) preconditioned tomato seeds before germination and (B) preconditioned tomato seeds after germination. Numbers on the left represent the total number of visible bands. Numbers on the bottom represent reference points (RP). $\mathrm{C}=$ untreated control; $\mathrm{E}=$ ethanol; $\mathrm{W}=$ water; $\mathrm{AM}=\mathrm{Ambiol}^{\circledR} ; \mathrm{BC}=\beta$-carotene $\mathrm{AA}=$ ascorbic acid.

Perhaps the most important physiological role of Ambiol ${ }^{\circledR}$ is to balance carbon allocation to both the root and shoot. Of all the antioxidants tested in this study, Ambiol ${ }^{\circledR}$ at 10 $\mathrm{mg} \cdot \mathrm{L}^{-1}$ treatment was the most effective at promoting growth in both the root and shoot of tomato seedlings. Water uptake depends on root activity, distribution, and size (Huang and Gao, 2000). Allocation of carbon to roots
This experiment provides evidence that Ambiol ${ }^{\circledR}$ may have a multifunctional role in drought protection. For example, previous experiments have suggested that the role of Ambiol $^{\circledR}$ in drought tolerance may be that of a membrane stabilizer in which Ambiol $^{\circledR}$ preconditioning significantly increased MII (Islam et al., 2003; Rajasekaran and Blake, 2002). However, preconditioning with only water also decreases membrane leakage, possibly through the reintroduction of phenolic compounds that may have leached through fractures in the testa, without an increase in photosynthesis or cellular growth. Because benefits to membrane stability are observed with water and Ambiol ${ }^{\circledR}$, it is suggested that there must be an alternate mechanism to membrane stability increasing growth from Ambiol ${ }^{\circledR}$ preconditioning.

Of the carotenoids tested, $\beta$-carotene at $1 \mathrm{mg} \cdot \mathrm{L}^{-1}$ was the most effective at alleviating several drought responses and promoting growth under drought. $\beta$-carotene was capable of promoting shoot DM production and leaf area expansion compared with untreated droughted seedlings. In addition to facilitated biomass accumulation under drought, $\beta$ carotene was very effective at allowing the tomato seedlings to continue photosynthesis, maintaining $87 \%$ of unstressed seedling photosynthesis at $\approx 5$ times higher than untreated plants under drought. Such a high photosynthetic rate resulted in WUE three times higher despite having twice the rate of transpiration as stressed untreated plants.

Although lycopene offered neither membrane protection nor increased $\mathrm{Pn}$, seed preconditioning at $0.1 \mathrm{mg} \cdot \mathrm{L}^{-1}$ lycopene had $70 \%$ higher DM production under drought. It is possible that the seedlings may have been able to maintain higher rates of photosynthesis before or during the early stages of drought, which then decreased near the end of the drought period when they may have begun to suffer from stress. Regardless, with such high DM production under drought, it was obvious that lycopene had some effect.

Lutein was relatively ineffective at promoting drought tolerance at any concentration. There were no significant improvements to shoot growth, leaf area expansion, photosynthesis, transpiration, or membrane protection. There was, however, an improvement in root growth from $1 \mathrm{mg} \cdot \mathrm{L}^{-1}$ preconditioning. In most cases, increased root growth results in improved water uptake and, subsequently, improved shoot growth (Huang and Gao, 2000). It remains unclear why lutein only promoted root growth, but it may be commercially important for certain crops.

Two ascorbic acid concentrations had $\approx 50 \%$ higher shoot DM and 5\% higher MII compared with untreated controls under drought. Both Pn and leaf area expansion was maintained, contributing to the increase in DM when treated with $1.0 \mathrm{mg} \cdot \mathrm{L}^{-1}$ ascorbic acid. Although the exact function of ascorbic acid preconditioning on photosynthetic regulation is unclear, the responses suggest that 
it enhanced carbon use efficiency under drought.

Of all responses observed, the $10 \mathrm{mg} \cdot \mathrm{L}^{-1}$ Ambiol ${ }^{\circledR}$ treatment was the most effective pretreatment. Higher drought tolerance using Ambiol $^{\circledR}$ was achieved through a combination of mechanisms, including membrane protection and carbon allocation. Both the 1.0 $\mathrm{mg} \cdot \mathrm{L}^{-1}$ ascorbic acid and $1.0 \mathrm{mg} \cdot \mathrm{L}^{-1} \beta$-carotene treatments were effective to a lesser degree. Lutein was effective at promoting root growth, but there were limited benefits to other response variables.

Despite the success of antioxidant seed preconditioning to promote drought tolerance, it seems unlikely that the effects were the result of direct antioxidant effects. Lutein, lycopene, and $\beta$-carotene are structurally similar and it was expected that each carotenoid would confer similar benefits to the tomato seedlings. However, only $\beta$-carotene and lycopene were effective at promoting growth during drought stress. It seems likely, therefore, that the beneficial drought tolerance effects may not be conferred directly by the carotenoids, but perhaps by downstream metabolites. This explanation would justify the difference in effectiveness of lutein, because it is created through the $\beta$-lycopene cyclase and $\varepsilon$-lycopene cyclase branch of the carotenoid pathway (Howitt and Pogson, 2006). The explanation that carotenoids act through downstream metabolites is further supported by the fact that lycopene and lutein, both powerful antioxidants in vitro, did not promote membrane protection under stress. Another possibility is that the mode of action of these antioxidants is not the result of direct action, because antioxidants were applied to seeds, but rather they induce certain molecular changes by evoking certain dormant genes.

Antioxidant-induced changes to the protein profile. With the exception of several $\beta$-carotene-induced proteins, there was very little difference in the protein profiles of pretreated seeds before germination. This result was likely because new proteins are synthesized after imbibition (Corbineau et al., 2000). Also, keto acids such as pyruvate and $\alpha$-ketoglutarate, which are important intermediates in respiration that are absent in the dry seed, can be reformed by deamination and transamination reactions during imbibition (Yamaya et al., 1984), potentially explaining the imbibition-related proteins found at RP 8.0 and RPs 8.9 to 9.8 .

Some proteins expressed in water and ethanol-treated seeds are similar to SPAtreated seeds. As a result of the severe desiccation associated with seeds, the cellular membranes are often unable to function normally at the start of imbibition. Combined with microscopic fractures in the testa, many compounds leach out of the seed during this time, including organic acids, amino acids, phenolic compounds, sugars, inorganic ions, and proteins (Duke and Kakefuda, 1981). Leached phenolic compounds may have antioxidant and antistress functions similar to SPAs; however, the effect must be small because water and ethanol treatments did not promote germination or growth under drought stress in a study with processing carrots (Briscoe, 2005). These proteins, however, are not related to promoting drought tolerance in SPA-treated seeds because the plants under control and ethanol control did not exhibit a similar protection to that of Ambiol $^{\circledR}$ or other antioxidant SPAs.

One particular point of interest is the large decrease in the total number of proteins easily detectable in SPA-treated seeds after germination compared with untreated or water/ ethanol-treated seeds. This may be related to the mobilization of certain cellular storage materials such as starch. Before radicle emergence, there is evidence that the metabolism of storage material begins to promote cell elongation, although the majority of storage material metabolization is often considered to occur after germination until the seedling is able to fix $\mathrm{CO}_{2}$ (Bewley and Black, 1985). The overall decrease in protein types could be linked to the acceleration in mobilization of the reserve materials, promoting early germination and accelerating growth until the seedling is able to photosynthesize.

More work is needed to investigate the changes in seed proteins. Because this was the first known experiment to determine the protein fingerprint of tomato seeds with and without SPAs, the fingerprint was taken over a broad range of $\mathrm{pH}$ (3.5 to 9.5). The next logical step would be to identify the $\mathrm{pI}$ values of the fingerprint reference points and repeat the procedure over a narrow $\mathrm{pH}$ range. Such a step would allow specific bands to be separated with much more confidence. Then the gene(s) responsible for protein synthesis and specific activated or inactivated proteins could be identified.

Physiological and commercial implications. The results from this study may have revealed another role for fruit ripening. In general, the ripening of fleshy fruits is considered to be important to render fruit attractive and palatable for seed-dispersing organisms (Giovanni, 2001). However, could there be a potential role for fruit ripening to serve as a natural source of seed preconditioning? It has been proven that the concentration of certain antioxidants changes during the ripening process. For example, ascorbic acid, glutathione, $\beta$-carotene, and lycopene increase during ripening in tomatoes (Giovanelli, 1999; Jimenez et al., 2002). In several berries, anthocyanins, total phenolics, and ascorbic acid increased during ripening and fermentation (Kalt et al., 1999; Wang and Lin, 2000). Perhaps as fruit becomes overmature, drops, and begins to decay, antioxidant levels change and there is a natural seed preconditioning taking place with possible accompanying benefits to the resulting seedlings. Further studies would be required to confirm this hypothesis.

In addition to physiological implications, there is potential commercial value for these findings. Several antioxidants (i.e., Ambiol ${ }^{\circledR}$, $\beta$-carotene, ascorbic acid) can promote drought tolerance. Also, certain antioxidants seem capable of promoting root growth, shoot growth, or both root and shoot growth. Any of these benefits could be of real use to producers. However, most antioxidant preconditioning studies have been limited to observing responses in seedlings (MacDonald et al., 2008; Rajasekaran and Blake, 1999, 2002). It would be interesting to see how long the effects persist in mature plants. Isoelectric focusing confirmed that there were changes in the protein profile, so it is possible that antioxidant preconditioning benefits may continue throughout the life of a plant and may potentially be passed to subsequent generations.

\section{Literature Cited}

Bartels, P.G. and C.W. Watson. 1978. Inhibition of carotene synthesis by fluridone and norflurazon. Weed Sci. 28:196-203.

Bewley, J.D. 1997. Seed germination and dormancy. Plant Cell 9:1055-1066.

Bewley, J.D. and M. Black. 1985. Seeds: Physiology of development and germination. Plenum Press, New York, NY.

Bradford, K.J. 1986. Manipulation of seed water relations via osmotic priming to improve germination under stress conditions. HortScience 21:1105-1112.

Briscoe, R. 2005. The physiology of various antistress, antioxidants, plant growth regulators, and mineral salts in promoting seed germination and seedling emergence under low soil temperature and soil moisture in processing carrots. MSc Thesis, Dalhousie University, Halifax, Nova Scotia, Canada.

Corbineau, F., M.A. Picard, J.A. Fougereux, F. Ladonne, and D. Come. 2000. Effects of dehydration conditions on desiccation tolerance of developing pea seeds as related to oligosaccharide content and cell membrane properties. Seed Sci. Res. 10:329-339.

Darlington, A., K. Vishnevetskaia, and T.J. Blake. 1996. Growth enhancement and anti-transpirant activity following seed treatment with a derivative of 5-hydroxybenzimidazole $\left(\right.$ Ambiol $\left.^{\circledR}\right)$ in four drought stressed agricultural species. Physiol. Plant. 96:217-222.

Duke, S.H. and G. Kakefuda. 1981. Role of the testa in preventing cellular rupture during imbibition of legume seeds. Plant Physiol. 3:449-456

FEMA-Federal Emergency Management Agency. 1995. National mitigation strategy: Partnerships for building safer communities. Washington, DC.

Giovanelli, G. 1999. Variation in antioxidant components of tomato during vine and post-harvest ripening. J. Sci. Food Agr. 79:1583-1588.

Giovanni, J. 2001. Molecular biology of fruit maturation and ripening. Annu. Rev. Plant Physiol. Plant Mol. Biol. 52:725-749.

Hames, B.D. 1990. One-dimensional polyacrylamide gel electrophoresis, p. 1-91. In: Hames, B.D. and D. Richwood (eds.). Gel electrophoresis of protein: A practical approach. Oxford University Press, New York, NY.

Howitt, C.A. and B.J. Pogson. 2006. Carotenoid accumulation and function in seeds and nongreen tissues. Plant Cell Environ. 29:435-445.

Huang, B. and H. Gao. 2000. Root physiological characteristics associated with drought resistance in tall fescue cultivars. Crop Sci. 40:196-203.

Islam, M.A., T.J. Blake, F. Kocacinar, and L. Rajasekaran. 2003. Ambiol ${ }^{\circledR}$, spermine, and aminoethoxyvinylglycine prevent water stress 
and protect membranes of Pinus strobus L under drought. Trees (Berl.) 17:278-284.

Jimenez, A., G. Creissen, B. Kular, J. Firmin, S. Robinson, M. Verhoeyen, and P. Mullineaux. 2002. Changes in oxidative processes and components of the antioxidant system during tomato fruit ripening. Planta 214:751-758.

Kalt, W., C.F. Forney, A. Martin, and R.L. Prior. 1999. Antioxidant capacity, vitamin C, phenolics, and anthocyanins after fresh storage of small fruits. J. Agr. Food Chem. 47:46384644.

Kaufmann, M.R. 1981. Water relations during drought, p. 55-70. In: Paleg, L.G. and D. Aspinall (eds.). Physiology and biochemistry of drought resistance in plants. Academic Press, Sydney, Australia.

Khan, A.A. 1992. Preplant physiological seed conditioning. Hort. Rev. (Amer. Soc. Hort. Sci.) 13:131-181.

Kirillova, I.G., A.S. Evsyunina, T.I. Puzina, and N.P. Korableva. 2003. Effects of Ambiol and 2chlorethylphosphonic acid on the content of phytohormones in potato leaves and tubers. Appl. Biochem. Microbiol. 39:210-214.

MacDonald, M.T. 2006. The physiological mechanisms of certain natural and synthetic antioxidant-induced drought tolerance in tomato seedlings. MSc Thesis, Dalhousie University, Halifax, Nova Scotia, Canada.

MacDonald M.T. and L.R. Rajasekaran. 2006. Ambiol $^{\circledR}$ enhances drought tolerance in flacca tomato mutant with wilty phenotype, p. 142. In: Proc Can Society Hort Sci.

MacDonald, M.T., L.R. Rajasekaran, J. Hoyle, and A.R. Robinson. 2008. Seed pre-conditioning with Ambiol ${ }^{\circledR}$, a derivative of 5-hydroxybenzimidazole, acclimates tomato (lycopersicon esculentum Mill.) seedlings to drought. Acta Hort. 774:355-362.

Ong, A.S.H. and E.S. Tee. 1992. Natural sources of carotenoids from plants and oils. Methods Enzymol. 213:142-167.

OTA-Office of Technology Assessment. 1993. Preparing for an uncertain climate. Vol. I. OTA-O-567. U.S. Government Printing Office, Washington, DC.

Phillips, D. 2002. The top ten Canadian weather stories for 2001. CMOS Bulletin 30:19-23.

Rajasekaran, L.R. and T.J. Blake. 1999. New plant growth regulators protect photosynthesis and enhance growth under Jack pine seedlings. J. Plant Growth Regul. 18:175-181.

Rajasekeran, L.R. and T.J. Blake. 2002. Seed pretreatment using a derivative of 5-hydroxybenzimidazole (AMBIOL ${ }^{\circledR}$ ) pre-acclimates carrot seedlings to drought. Can. J. Plant Sci. 82:195202.

Rajasekaran, L.R., A. Stiles, and T.J. Blake. 2005. The effects of natural and synthetic seed preconditioning agents (SPAs) in hastening seedling emergence and enhancing yield and quality of processing carrots. Sci. Hort. 106:25-37.
Rajasekaran, L.R., A. Stiles, M.A. Surette, A.V. Sturz, T.J. Blake, C. Caldwell, and J. Nowak. 2004. Stand establishment technologies in processing carrots. Acta Hort. 631:105116.

Santrucek, M. and J. Krepelka. 1988. AntioxidantsPotential chemotherapeutic agents. Drugs Future 13:974-996.

Shulze, E.D. 1986. Whole plant responses to drought. Aust. J. Plant Physiol. 13:127-141.

Voronina, S.S., G.P. Zhizhina, and E.L. Lozovskaya. 2001. Biophysical aspects of the action of plant growth regulators Ambiol ${ }^{\circledR}$ and fonk. Biofizika 46:34-38.

Wang, S.W. and H. Lin. 2000. Antioxidant activity in fruits and leaves of blackberry, raspberry, and strawberry varies with cultivar and development stage. J. Agr. Food Chem. 48:140146.

Wheaton, E.E., L.M. Arthur, B. Chorney, S. Shewchuk, J. Thorpe, J. Whiting, and V. Wittrock. 1992. The prairie drought of 1988. Climatol. Bull. 26:188-205.

Wilhite, D.A. and O. Vanyarkho. 2000. Drought: pervasive impacts of a creeping phenomenon, p. 245-255. In: Wilhite D.A. (ed.). Drought: A global assessment. Routledge Publishers, London, UK.

Yamaya, T., A. Oaks, and H. Matsumoto. 1984. Characteristics of glutamate dehydrogenase in mitochondria prepared from corn shoots. Plant Physiol. 76:1009-1013. 